\title{
Exogenous hyperglucagonaemia in insulin controlled diabetic rats increases urea excretion and nitrogen loss from organs
}

\author{
T.P.Almdal and H. Vilstrup \\ Divisions of Hepatology and Experimental Pathology, Rigshospitalet, Copenhagen, Denmark
}

\begin{abstract}
Summary. In order to study the effect of hyperglucagonaemia on nitrogen metabolism in diabetes, zinc protamin glucagon $60 \mu \mathrm{g}$ was injected subcutaneously 3 times daily for 4 weeks into streptozotocindiabetic rats $(n=5)$, adequately treated with long acting insulin. This raised the plasma concentration of glucagon to $725 \pm 125$ (mean \pm SEM), which is not different from that found in portal blood of uncontrolled diabetic rats: $400 \pm 75 \mathrm{ng} / 1$. The controls were 5 diabetic rats treated with insulin alone and 5 non-diabetic rats.

Compared with control rats the nitrogen balance was reduced $(p<0.05)$ and the nitrogen contents of carcass, heart, intestines, and kidneys were reduced by $15-30 \%(p<0.05)$ in the glucagon treated rats. The hepatic capacity of urea synthesis and the alanine elimination rate were determined in the 3 above-mentioned groups, and confirmed in 3 identical groups followed for only 2 weeks; and in addition in a group of glucagon treated diabetic rats, where the long acting glucagon was substituted by neutral insulin the last two days before investigation. The capacity of urea- $\mathrm{N}$ synthesis and
\end{abstract}

the alanine elimination rate were, respectively, in control rats: $9.6 \pm 0.8$ and $5.9 \pm 0.3 \mu \mathrm{mol} /(\min 100 \mathrm{~g}$ body weight $)$, in insulin treated diabetic rats: $8.5 \pm 0.7$ and $5.4 \pm 0.6$ $\mu \mathrm{mol} /(\min 100 \mathrm{~g}$ body weight), in glucagon treated rats: $6.3 \pm 0.4$ (lower than controls, $p<0.05$ ) and $10.4 \pm 0.4$ (higher than controls, $p<0.05) \mu \mathrm{mol} /(\min 100 \mathrm{~g}$ body weight $)$, and in glucagon treated rats given neutral insulin: $20.7 \pm 1.6$ and $10.9 \pm 0.3 \mu \mathrm{mol} /(\min 100 \mathrm{~g}$ body weight) (both higher than controls, $p<0.05$ ). Hyperglucagonaemia in itself leads to loss of nitrogen from organs, probably by an increased hepatic conversion of amino-nitrogen to urea-nitrogen, as evidenced by the increased urea excretion. This proceeds despite an insulin induced decrease in the capacity of urea synthesis and may thus rather be attributed to changes in the affinity of urea synthesis for amino-nitrogen.

Key words: Experimental diabetes, urea synthesis, nitrogenmetabolism, nitrogen-balance, insulin therapy, glucagon.
In diabetes hyperglucagonaemia is seen [1]. Although glucagon has been demonstrated to increase the hepatic glucose production, this effect is transient [2]. However, in spite of a normal glucose production an increased hepatic amino acid elimination has been demonstrated in diabetic patients [3]. Glucagon can increase the hepatic conversion of alanine into glucose and urea [4], and normalisation of the diabetic hyperglucagonaemia leads to a decrease in the urea excretion [1]. Taken together these observations suggest that the hyperglucagonaemia of diabetes may affect amino acid metabolism.

In uncontrolled experimental diabetes with hyperglucagonaemia, protein is lost from most organs, and more urea is synthesized at any given amino acid concentration $[5,6]$. It is not known whether this is an effect of glucagon only on the liver, or is due also to increased release of amino acids from organs into the blood. Likewise, is it not known whether hyperglucagonaemia in itself by any of these two mechanisms can lead to loss of nitrogen from organs. Insulin normalises plasma glucagon and abolishes all the above mentioned abnormalities [7].

The purpose of the present study was to study selectively the effect of hyperglucagonaemia on amino nitrogen conversion in diabetic rats. This was done by measuring the nitrogen contents of organs and the kinetics of urea synthesis. Diabetic rats treated with insulin were given exogenous glucagon so as to raise the glucagon concentration to the level of uncontrolled diabetes.

\section{Material and methods}

\section{Animals}

After an overnight fast diabetes was induced in female Wistar rats of $220 \mathrm{~g}$ by intravenous injection of streptozotocin (Zanosar, Upjohn Co, Kalamazoo, Mich, USA), $75 \mathrm{mg} / \mathrm{kg}$ body weight (BW) dissolved in isotonic saline at $\mathrm{pH} 4.5$. The control rats received the vehicle. 
The rats were kept in a thermostated room with a $12 \mathrm{~h}$ light/dark cycle. They were kept in their cages for one week before injections and had free access to water and food, which in the metabolic cages was pulverized, and in the ordinary cages was pellets, in both cases of a standard diet (Altromin Werke, Lage, FRG).

\section{Protocols}

For nitrogen $(\mathrm{N})$ balance, organ nitrogen content studies, and initial studies of the capacity of urea-N synthesis and the alanine elimination rate, rats were kept single in metabolic cages for 4 weeks after injection of streptozotocin/saline. There were three protocols:

Ia: Control rats $(n=5)$ : Animals given saline.

IIa: Diabetic rats $(n=5)$ : Animals given streptozotocin and optimally controlled with ultralente insulin.

IIIa; Diabetic + glucagon rats $(n=5)$ : Animals given streptozotocin optimally controlled with ultralente insulin, and given exogenous glucagon.

In order to consolidate the results concerning the capacity of urea synthesis and alanine elimination and to repeat these without the presence of the ultralente insulin, other rats were kept in groups of 4 in ordinary cages for 2 weeks after injection of streptozotocin/saline according to the following protocols:

Ib: Control rats $(n=5)$ : As in Ia.

IIb: Diabetic rats $(n=5)$ : As in IIa.

IIIb: Diabetic + glucagon rats $(n=5)$ : As in IIIa.

IV: Diabetic + glucagon + neutral insulin rats $(n=5)$ : As in IIIb, just given neutral insulin on days 11 and 12 .

\section{Insulin therapy}

The criterion for diabetes was glucosuria of above $30 \mathrm{mmol} / 24 \mathrm{~h}$. Forty-eight hours after streptozotocin administration insulin therapy was started, using a long acting insulin preparation heat treated Insulin Ultralente bovine, pH 5.5 (Novo Industries, Copenhagen, Denmark) $[8,9]$. Initially, the insulin dose was 8 IU per day. Within the first week this was gradually reduced to 4 IU per day. Then the dosage was adjusted according to tail blood glucose values determined daily with Dextrostix and Ames Reflectometer. Blood glucose values between 3.0 and $7.0 \mathrm{mmol} / 1$ were accepted without leading to changes in the insulin dosage. Neutral insulin (Actrapid, Novo, Denmark) was given to the rats of protocol IV on days 11 and 12 at 16.00 and 24.00 hours. The total dosage of neutral insulin was $2 / 3$ of that given as ultralente insulin. The last dosage of insulin was given $24 \mathrm{~h}$ before investigations.

\section{Glucagon treatment}

Zinc protamin glucagon (ZPG) $(10 \mathrm{mg} / \mathrm{ml})$ (Novo) was used. In a preliminary experiment 16 rats were made diabetic as above and left without insulin treatment. Portal blood was taken 1,2,3 and 4 weeks later. The portal glucagon concentration was $400 \pm 75 \mathrm{ng} / \mathrm{l}$ (mean \pm SEM), irrespective of the duration of diabetes.

In another preliminary experiment 4 diabetic rats, optimally treated with insulin as above, were injected s.c. with ZPG $60 \mu \mathrm{g}$ 3 times daily at 8 -h intervals for 5 days. Then blood was taken for determination of glucagon concentrations $1,3,5$, and $7 \mathrm{~h}$ after the last injection of ZPG. The glucagon concentration was $725 \pm 75 \mathrm{ng} / 1$ (mean $\pm S E M$ ) and constant during these $7 \mathrm{~h}$.

Injection of ZPG $60 \mu \mathrm{g} 3$ times daily thus leads to a constant hyperglucagonaemia of the same magnitude as that seen in the portal blood of uncontrolled diabetic rats.

The rats given exogenous glucagon (protocols III a and b, IV) were treated according to this regimen.

\section{Determination of nitrogen and energy balances}

On the last two days of every week the following were determined (Protocols Ia, IIa and IIIa):

Nitrogen-balance $(\mathrm{mmol} / 24 \mathrm{~h})=$ food amount $(\mathrm{g}) \times$ food $\mathrm{N}$-concentration $(\mathrm{mmol} / \mathrm{g}$ ) - (urine $\mathrm{N}+$ feces $\mathrm{N}$ contents)

Energy balance $(\mathrm{KJ} / 24 \mathrm{~h})=$ food $(\mathrm{g}) \times$ caloric value $(13 \mathrm{KJ} / \mathrm{g})-$ glucose lost in urine $(\mathrm{mmol}) \times$ caloric value $(2.9 \mathrm{KJ} / \mathrm{g})$

\section{Nitrogen contents in organs}

After 4 weeks the capacity of urea synthesis and the rate of alanine elimination were determined in protocols Ia, IIa, and IIIa; the animals were killed and dissected into: kidneys, liver, heart, intestines, and carcass (comprising) muscles, bones, and nervous system). Intestines and carcass were homogenised and samples were frozen. Kidneys, livers, and hearts were frozen in toto. Details are given in [5]

\section{Analyses}

Blood urea concentration was measured by the urease-Berthelot method [10] and blood total alpha-amino- $N$ concentration by the dinitrofluorobenzene method [11]. Glucose concentration in blood and in urine was measured by the glucose oxidase technique, by a glucose analyser (Yellow Springs Instruments, Yellow Springs, Ohio, USA). Plasma insulin and glucagon concentrations were determined by radio-immunoassay $[12,13]$, glucagon after ethanol extraction.

$\mathrm{N}$-contents in excreta and in organs were determined by the micro Kjeldahl technique as previously described [5].

\section{The Capacity of Urea-Nitrogen Synthesis (CUNS) and the alanine elimination rate (EALA)}

After 2 (protocols Ib, IIb, IIIb and IV) or 4 (Protocols Ia, IIa, IIIa) weeks CUNS and EALA were determined during alanine loading to steady state total amino acid concentration between 8 and $11 \mathrm{mmol} / 1$ as previously described in details [6].

CUNS $(\mu \mathrm{mol} /(\min 100 \mathrm{~g} \mathrm{BW}))$ was calculated as: $\mathrm{CUNS}=\mathrm{dcu} / \mathrm{dt} \times 0.63 \times \mathrm{BW} \times(1-0.20)$,

where $\mathrm{dcu} / \mathrm{dt}$ is the slope of the linear regression analysis of urea concentration on time, $0.63 \times \mathrm{BW}$ is the distribution volume of urea, and 1-0.20 the fractional intestinal hydrolysis of newly synthesized urea. There was no urinary excretion since the rats were nephrectomised immediately before amino acid loading.

EALA $(\mu \mathrm{mol} /(\min 100 \mathrm{~g} \mathrm{BW}))$ was calculated as:

$\mathrm{EALA}=\mathrm{Ia}-(\mathrm{dca} / \mathrm{dt} \times 0.50 \times \mathrm{BW})$

where Ia is the alanine infusion rate, $\mathrm{dca} / \mathrm{dt}$ is the slope of the linear regression of the arterial blood alpha-amino- $\mathrm{N}$ concentration on time and $0.50 \times \mathrm{BW}$ the volume of distribution of alanine.

Results with regard to hormone values, fasting alpha amino nitrogen, the capacity of urea $\mathrm{N}$-synthesis, and the alanine elimination rate were identical in protocols Ia and Ib (control rats) and the results are therefore given together in Tables 1 and 2. The same applies to protocols IIa and IIb (insulin treated diabetic rats) and IIIa and IIIb (insulin treated diabetic rats given exogenous glucagon).

\section{Statistical analysis}

Differences between groups were evaluated by Student's t-test of mean values. A $p$ value smaller than 0.05 was considered statistically significant. 
Table 1. The fasting blood glucose, the fasting total alpha amino-N (A-A-N), the capacity of urea-N synthesis (CUNS), and the alanine elimination rate (EALA) in the seven protocols investigated. Details of the protocols are given in Materials and methods. Results are mean \pm SEM

\begin{tabular}{|c|c|c|c|c|}
\hline $\begin{array}{l}\text { Protocol } \\
\text { No. and Type }\end{array}$ & $\begin{array}{l}\text { Fasting } \\
\text { Blood Glucose } \\
(\mathrm{mmol} / 1)\end{array}$ & $\begin{array}{l}\text { Fasting A-A-N } \\
(\mathrm{mmol} / \mathrm{l})\end{array}$ & $\begin{array}{l}\text { CUNS } \\
\left(\mu \mathrm{mol} \cdot \min ^{-1}\right. \\
\left.100 \mathrm{~g} \mathrm{BW}^{-1}\right)\end{array}$ & $\begin{array}{l}\text { EALA } \\
\left(\mu \mathrm{mol} \cdot \min ^{-1}\right. \\
\left.100 \mathrm{~g} \mathrm{BW}^{-1}\right)\end{array}$ \\
\hline $\begin{array}{l}\text { Ia and Ib } \\
\text { Control }\end{array}$ & $4.5 \pm 0.3$ & $5.2 \pm 0.3$ & $9.6 \pm 0.8$ & $5.9 \pm 0.3$ \\
\hline $\begin{array}{l}\text { IIa and IIb } \\
\text { Diabetic }\end{array}$ & $5.1 \pm 1.0$ & $5.4 \pm 0.3$ & $8.5 \pm 0.7$ & $5.4 \pm 0.6$ \\
\hline $\begin{array}{l}\text { IIIa and IIIb } \\
\text { Diabetic + glucagon }\end{array}$ & $6.0 \pm 1.2$ & $2.1 \pm 0.4^{\mathrm{a}}$ & $6.3 \pm 0.4^{\mathrm{a}}$ & $10.4 \pm 0.4^{b}$ \\
\hline $\begin{array}{l}\text { IV } \\
\text { Diabetic + glucagon } \\
+ \text { neutral insulin }\end{array}$ & $12.5 \pm 0.8^{b}$ & $1.4 \pm 0.2^{\mathrm{a}}$ & $20.7 \pm 1.6^{b}$ & $10.9 \pm 0.3^{b}$ \\
\hline
\end{tabular}

${ }^{\mathrm{a}}$ Lower than control $(p<0.01) ;{ }^{\mathrm{b}}$ Higher than control $(p<0.01)$

Table 2. Fasting and alanine stimulated glucagon and insulin concentrations in the seven protocols investigated. Details of the protocols are given in Materials and methods. Results are mean \pm SEM

\begin{tabular}{lllll}
\hline & Glucagon $(\mathrm{ng} / \mathrm{l})$ & & Insulin (mU/l) \\
\cline { 2 - 4 } $\begin{array}{l}\text { Protocol } \\
\text { No. and Type }\end{array}$ & Fasting & $\begin{array}{l}\text { Alanine } \\
\text { stimulated }\end{array}$ & Fasting & $\begin{array}{l}\text { Alanine } \\
\text { stimulated }\end{array}$ \\
\hline $\begin{array}{l}\text { Ia and Ib } \\
\text { Controls }\end{array}$ & $76 \pm 15$ & $480 \pm 70$ & $10.8 \pm 2.9$ & $29.4 \pm 5.3$ \\
$\begin{array}{l}\text { IIa and IIb } \\
\text { Diabetic }\end{array}$ & $73 \pm 28$ & $352 \pm 100$ & $32.0 \pm 7.0^{\mathrm{b}}$ & $25.6 \pm 4.3$ \\
$\begin{array}{l}\text { IIIa and IIIb } \\
\text { Diabetic+glucagon }\end{array}$ & $879 \pm 155^{\mathrm{a}}$ & $570 \pm 105$ & $37.5 \pm 5.3^{\mathrm{b}}$ & $23.0 \pm 3.0$ \\
$\begin{array}{l}\text { IV } \\
\text { Diabetic+glucagon } \\
+ \text { neutral insulin }\end{array}$ & $544 \pm 76^{\mathrm{a}}$ & $492 \pm 112$ & $7.5 \pm 1.6$ & $\mathbf{1 0 . 2 \pm 2 . 1}$ \\
\hline
\end{tabular}

${ }^{\mathrm{a}}$ Higher than controls $(p<0.05) ;{ }^{\mathrm{b}}$ Higher than controls $(p<0.05)$

When more than two groups are compared there is a risk of mass significance. Therefore, the significance level was adjusted according

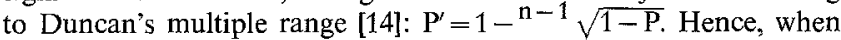
$n=3$ groups were compared, $\mathrm{P}^{\prime}=0.025$, and when $n=4$ groups were compared $\mathrm{P}^{\prime}=0.01$.

Differences among variables were tested by one-way analyses of variance (one way ANOVA).

\section{Results}

The diabetic animals had a glucose excretion of about $40 \mathrm{mmol} / 24 \mathrm{~h}$ before insulin therapy. On insulin therapy (protocol IIa) the glucose excretion was $5.7 \pm 0.8 \mathrm{mmol} / 24 \mathrm{~h}$ (mean $\pm \mathrm{SEM})$; in the diabetic rats also given exogenous glucagon (Protocol IIIa) it was $6.7 \pm 0.8 \mathrm{mmol} / 24 \mathrm{~h}$. The mean insulin dosage was $1.81 \mathrm{IU} /(24 \mathrm{~h} 100 \mathrm{~g} \mathrm{BW})$, the same when glucagon was given.

The energy balances were identical in all protocols (Ia, IIa and IIIa) throughout the study at about $240 \mathrm{KJ} / 24 \mathrm{~h}$.

The insulin treated diabetic rats (Protocol IIa) gained about $6 \mathrm{~g} /$ week in body weight during the
4 weeks, as did the control rats (Protocol Ia). The rats given glucagon (protocol IIIa) had a constant weight for the first week, during the next two weeks they lost $8 \mathrm{~g} /$ week, and during the final week they maintained a body weight of about $200 \mathrm{~g}$, i. e. $10 \%$ lower than the initial weight.

The N-balance was identical and positive throughout the study period in control and diabetic rats (Fig.1). In the diabetic rats given glucacon it was increasingly less positive with time $(p<0.05$, one way ANOVA).

In the control animals and diabetic animals the daily N-loss was identical throughout the study (Fig. 2). Fifty percent was excreted as urea-N, $10 \%$ as non urea urinary $\mathrm{N}$, and $40 \%$ in feces. Glucagon increased the daily total $\mathrm{N}$ loss by $25-35 \%$ and this was accounted for by an increase in urea excretion $(p<0.05)$.

The organ $\mathrm{N}$ contents of the control and insulin treated diabetic rats were identical (Table 3). In the diabetic animals given exogenous glucagon the carcass and organ nitrogen contents decreased by $15-30 \%$, except in the liver. 


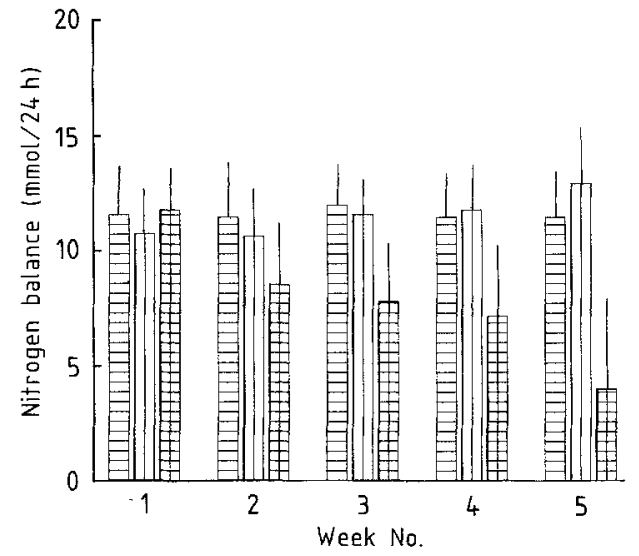

Fig. 1. The calculated nitrogen balance of control rats (目), diabetic rats optimally controlled with insulin for 4 weeks (田), and diabetic rats optimally controlled with insulin and in addition given glucagon for 4 weeks ( $($ ). Results are given as mean and 2 SEM

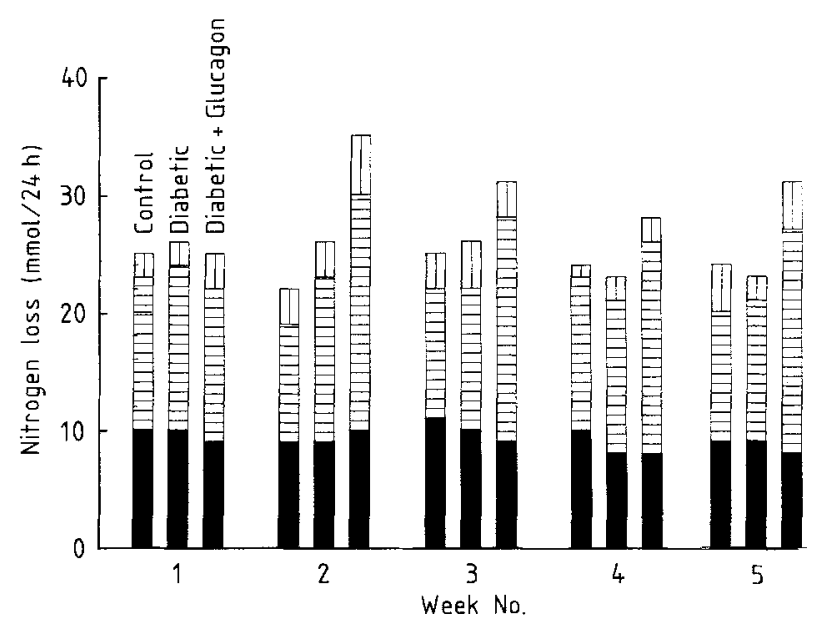

Fig. 2. The amount of $\mathrm{N}$ lost in feces (E) and in urine, as urea (E) and as other nitrogen containing substances (四) in control rats, diabetic rats optimally controlled with insulin (Diabetic) for 4 weeks and diabetic rats optimally controlled with insulin and in addition given glucagon (Diabetic + glucagon) for 4 weeks. Results are given as means

The fasting blood alpha amino-nitrogen concentration was identical in control rats and in diabetic rats not given glucagon (Table 1). Glucagon decreased the fasting alpha amino-nitrogen concentration by $65 \%$.

The capacity of urea- $\mathrm{N}$ synthesis was identical in the control rats (protocols Ia and b) and in the diabetic rats (protocols IIa and b) (Table 1). In the diabetic rats given glucagon (protocols IIIa and b), the capacity of urea- $\mathrm{N}$ synthesis was $65 \%$ of that of the control rats, whereas it increased 2.5-fold in the diabetic rats given ultralente followed by neutral insulin and given glucagon (protocol IV).

The alanine elimination rate was identical in control rats and in diabetic rats irrespective of insulin regimen (Table 1). Glucagon doubled the alanine elimination irrespective of insulin regimen.

The fasting blood glucose concentrations were identical in control rats, in diabetic rats given
Table 3. Nitrogen ( $\mathrm{N}$ ) contents of carcass (muscles), heart, intestines, liver and kidneys from control rats (control), diabetic rats optimally controlled with insulin for 4 weeks (diabetic) and diabetic rats optimally controlled with insulin for 4 weeks and in addition given glucagon $60 \mu \mathrm{g} 3$ times daily for 4 weeks (diabetic + glucagon). Details on the three protocols are given in Materials and methods. Results are mean \pm SEM

\begin{tabular}{lccc}
\hline & $\begin{array}{l}\text { Control } \\
\text { (protocol Ia) } \\
(n=5)\end{array}$ & $\begin{array}{l}\text { Diabetic } \\
\text { (protocol Ila) } \\
(n=5)\end{array}$ & $\begin{array}{l}\text { Diabetic+Glu- } \\
\text { cagon (protocol } \\
\text { Illa) }(n=5)\end{array}$ \\
\hline Carcass N (mmol) & $362 \pm 7$ & $371 \pm 11$ & $305 \pm 10^{\mathrm{a}}$ \\
Heart N (mmol) & $1.42 \pm 0.07$ & $1.47 \pm 0.03$ & $1.25 \pm 0.04^{\mathrm{a}}$ \\
Intestine N (mmol) & $30.0 \pm 1.4$ & $29.0 \pm 1.5$ & $19.4 \pm 1.4^{\mathrm{a}}$ \\
Liver N (mmol) & $17.2 \pm 0.5$ & $17.5 \pm 1.1$ & $14.6 \pm 0.9$ \\
Kidney N (mmol) & $3.68 \pm 0.28$ & $3.71 \pm 0.16$ & $2.63 \pm 0.12^{\mathrm{a}}$ \\
\hline
\end{tabular}

${ }^{\text {a }}$ Diabetic + glucagon smaller than control and diabetic $(p<0.01)$

ultralente insulin, and in diabetic rats given ultralente insulin and glucagon, whereas it increased 2-fold in the diabetic rats given neutral insulin the two last days before investigations (Table 1 ).

The fasting glucagon concentration was identical in control rats (Protocols Ia and b) and insulin treated diabetic rats (protocol IIa and b) (Table 2). Exogenous glucagon (protocols IIla and $b$, IV) increased fasting glucagon about 10 -fold. The glucagon concentrations following alanine load were not different among the groups, but tended to fall in the rats given exogenous glucagon.

The fasting insulin concentration increased 3 to 4 fold on ultralente insulin (Protocols IIa and b and IIIa and b) compared to controls, whereas it was not different from controls on ultralente followed by neutral insulin (protocol IV, Table 2). Alanine increased the insulin concentration 3 -fold in the control rats, where it reached the same values as in the diabetic rats only given ultralente insulin. In diabetic rats, irrespective of insulin regimen, there was no increase in insulin concentration on alanine infusion.

\section{Discussion}

The basal hyperglucagonaemia of uncontrolled and poorly controlled diabetes [1] normalises on strict insulin regimens [15]. Accordingly, the hyperglucagonaemia is in vitro secondary to lack of insulin within the islets of Langerhans [16]. It has been demonstrated in normal and diabetic postabsorptive man that glucagon can increase total hepatic glucose production, but the effect is only transient [2].

The splanchnic uptake of gluconeogenetic precursors only accounts for about $20 \%$ of the total glucose production in normal man, but for $30 \%$ in diabetic patients [3]. When glucagon is raised 4-fold for $3 \mathrm{~h}$, during fixed basal insulin concentration, the total glucose production initially triples, but gradually returns to near basal levels within $3 \mathrm{~h}$. In contrast, the rate of 
conversion of alanine to glucose progressively triples over $3 \mathrm{~h}$ [17]. On repeating this experiment with a normal insulin release pattern, the glucose production shows the same pattern, but the rate of conversion of alanine to glucose remains unchanged [18]. Nonetheless, the net hepatic alanine uptake increased by about 50\% [18]. Since urea production was not measured, it is not known whether the hepatic alanine metabolism was influenced by insulin. The present study was undertaken in order to study, by means of urea synthesis, whether glucagon increases the hepatic metabolism of amino acids to urea, irrespective of insulin concentrations; and whether this leads to whole body catabolism.

The study shows that hyperglucagonaemia in itself leads to loss of nitrogen from organs and increased urea excretion in insulin treated diabetic rats. This occurred at comparable glucoregulation as documented by the identical glucose excretion, and on the same insulin dosage. The insulin treatment resulted in a complete normalisation of organ $\mathrm{N}$ contents as previously demonstrated [7].

The food intake and energy balance of the three groups of animals were identical so that the organ $\mathrm{N}$ loss was not due to dietary differences.

The rats given glucagon had no lack of insulin and lost nitrogen from all organs except the liver. This pattern is different from that of uncontrolled diabetes, where $\mathrm{N}$ is lost only from skeletal and heart muscle [5], and where the total $\mathrm{N}$ loss is still twice as large as that of the glucagon treated diabetic rats. The difference seems to be that lack of insulin leads to increased release of amino acids from the organs [19]. Glucagon in itself can affect the tissue protein metabolism and lead to nitrogen loss in normal rats, but at much higher plasma concentrations than those of the present study [20]. Glucagon reduced the total amino acid concentration to about one-third, and lack of amino acids in the presence of insulin leads to loss of protein from skeletal muscle [21]. Whether, and to what extent, the nitrogen contents of other organ systems depends on the low amino acid concentration has not been examined; but the present study suggests such a dependence of all tissues.

This mechanism may explain how amino- $\mathrm{N}$ was extracted from the tissues, made available to the liver, and lost by urea synthesis. The decreased blood amino- $\mathrm{N}$ concentration (Table 2 ) shows that amino- $\mathrm{N}$ was removed faster from the blood pool by the liver than released into the pool from the tissues. The primary phenomenon, therefore, may be a changed hepatic kinetics of amino- $\mathrm{N}$ conversion, i.e. urea synthesis or hepatic alanine uptake for other purposes.

The capacity of urea synthesis was identical in control rats and insulin treated rats. In the rats given glucagon and neutral insulin for the last two days before investigation, the capacity of urea synthesis increased 2.5 -fold as in uncontrolled diabetes $[5,6]$ and in nor- mal rats given exogenous glucagon [22]. This shows that the increased capacity of urea- $\mathrm{N}$ synthesis was a consequence of the hyperglucagonaemia.

In the glucagon treated rats given ultralente insulin throughout the study the capacity of urea synthesis was lower than in control rats. The insulin and glucagon treated rats had high insulin levels at the investigation, and insulin decreases CUNS in normal rats, by both reducing endogenous supply of amino acids and by a direct effect on urea cycle [22]. The present study shows that during constant high glucagon levels, the effect of insulin on CUNS overrides that of glucagon. However, the insulin concentration was also high in the insulin treated diabetic animals not given glucagon (Table 2), and in these rats the capacity of urea synthesis was not different from that of control rats. Therefore, high insulin levels cannot be the only explanation for the decreased capacity of urea synthesis in rats given exogenous glucagon, and this finding remains unexplained.

Glucagon nearly doubled the alanine metabolism, irrespective of insulin regimen. Therefore, the reduced capacity of urea synthesis during hyperinsulinaemia must be due mostly to an effect of insulin on the urea cycle. It is, however, not known how insulin acts and what happens to the alanine- $\mathrm{N}$ eliminated and not converted into urea-N. The alanine was evidently not taken up by extrahepatic tissues, as the animals were nitrogen wasters.

Insulin increases the hepatic protein synthesis [24], and therefore part of the explanation may be that alanine within the hepatocyte was diverted towards protein synthesis. However, this explanation is less attractive, since the other diabetic rats that received the same amount of insulin had normal CUNS. The reason for the discrepancy is not evident. It has been demonstrated that high alanine concentrations in normal hepatocytes inhibit urea cycle activity [25] and higher intracellular alanine concentrations may be expected in the glucagon treated rats.

The control rats and the insulin treated diabetic rats excreted about $12 \mathrm{mmol}$ of urea- $\mathrm{N} / 24 \mathrm{~h}$ corresponding to $4.1 \mu \mathrm{mol} /(\mathrm{min} 100 \mathrm{~g} \mathrm{BW})$ and the glucagon treated diabetic rats excreted about $18 \mathrm{mmol}$ of urea- $\mathrm{N} / 24 \mathrm{~h}$ corresponding to $6.2 \mu \mathrm{mol} /(\min 100 \mathrm{~g}$ BW). Thus urea synthesis in control and insulin treated diabetic rats took place at a rate of about half capacity, whereas it proceeded at a rate close to capacity in the glucagon treated diabetic rats, although the blood amino- $\mathrm{N}$ concentration was lower. This indicates that there were changes in the kinetics of urea synthesis other than an increased capacity of urea synthesis. There was an increased affinity for urea synthesis at low amino acid concentrations, i.e. a decreased $\mathrm{Km}$. This change, in contrast to the increase in CUNS, was not suppresible by insulin.

The present study demonstrates that hyperglucagonaemia leads to loss of body nitrogen, partly be- 
cause of an increased hepatic amino nitrogen elimination. The effect depends on depletion of the blood of amino acids by the liver, and an increased amino acid release by the tissues, favoured by the low amino acid concentration. This conclusion is in agreement with studies on diabetes, suggesting that chronic hyperglucagonaemia, without increasing the total hepatic glucose production, increases the fraction of the hepatic glucose production that derives from amino acids. Thus, hyperglucagonaemia in otherwise well controlled diabetes may be important for body nitrogen wasting.

Acknowledgments. The skillful assistance by technicians B. Krog, L. Hansen, K.Priisholm, I.Petersen, B. Fich, and E. Nietsch is hereby gratefully acknowledged. Our thanks are due to technician A. Lieth, Department of Clinical Chemistry, Rigshospitalet, who kindly performed the analysis of urine urea. This study was supported by grants from The Danish Foundation for the Advancement of Medical Sciences, The Danish Hospital Foundation for Medical Research (Region of Copenhagen, The Faeroe Islands, and Greenland) and The P.Carl Petersen Foundation. Novo, Denmark, kindly supplied ionated insulin and glucagon, antisera, and Zink Protamin Glucagon.

\section{References}

1. Raskin P, Unger R (1978) Hyperglucagonemia and its suppression. N Engl J Med 299: 433-436

2. Bomboy JD, Lewis SB, Lacy WW, Sinclair-Smith BC, Liljenquist JE (1977) Transient stimulatory effect of sustained hyperglucagonemia on splanchnic glucose production in normal and diabetic man. Diabetes 26: 177-184

3. Wahren J, Felig P, Cerasi E, Luft R (1972) Splanchnic and peripheral glucose and amino acid metabolism in diabetes mellitus. J Clin Invest 51: 1870-1878

4. Mallette LE, Exton JH, Park CR (1969) Control of gluconeogenesis from amino acids in the perfused liver. $J$ Biol Chem 244: $5713-5723$

5. Almdal T, Vilstrup H (1987) Effects of diabetes and diet on the nitrogen loss from organs and the capacity of the urea synthesis in diabetes. Diabetologia 30: 952-956

6. Almdal T, Petersen KF, Hansen BA, Vilstrup H (1986) Increased capacity of urea synthesis in streptozotocin diabetes in rats. Diabetologia $29: 812-816$

7. Almdal T, Vilstrup H (1988) Strict insulin treatment normalizes the organ nitrogen contents and the capacity of urea- $\mathrm{N}$ synthesis in experimental diabetes in rats. Diabetologia 31: 114-118

8. Rasch R (1979) Control of blood glucose levels in streptozotocin diabetic rat using a very long acting heat treated insulin. Diabetologia 16: 185-190

9. Jacobsen J (1979) Early and preventable changes of peripheral nerve structure and function in insulin-deficient rats. $J$ Neurol Neurosurg Psychiatry 42: 509-518

10. Fawcett JK, Scott JE (1960) A rapid and precise method for determination of urea. J Clin Pathol 13: 156-159

11. Goodwin JF (1970) Spectophotometric quantitation of plasma and urinary amino nitrogen with flurodinitrobenzene. Stand Methods Clin Chem 6: 89-98

12. Heding LG (1972) Determination of total serum insulin (IRI) in insulin-treated diabetic patients. Diabetologia 8: 260-266

13. Heding LG (1971) Radioimmunological determination of pancreatic and gut glucagon in plasma. Diabetologia 7: 10-17

14. Duncan DB (1957) Multiple range test for correlated and heteroscedastic means. Biometrics 164-204

15. Raskin P, Pietri A, Unger R (1979) Changes in glucagon levels after four to five weeks of glucoregulation by protable insulin infusion pumps. Diabetes 28: 1033-1035

16. Maruyama H, Hisatomi A, Orci L, Grodshy GM, Unger RH (1984) Insulin within islets is a physiologic glucagon release inhibitor. J Clin Invest 74: 2296-2299

17. Cherrington AD, Williams PE, Shulman GI, Lacy WW (1981) Differential time course of glucagon's effects on glycogenolysis and gluconeogenesis in the conscious dog. Diabetes 30: 180-187

18. Steiner K, Mouton S, Williams PE, Lacy WW, Cherrington AD (1986) Relative importance of first- and second-phase insulin secretion in glucose homeostasis in concious dog. Diabetes 35: 776-784

19. Pain VM, Garlick PJ (1974) Effects of streptozotocin diabetes and insulin treatment on the rate of protein synthesis in tissues of the rat in vivo. J Biol Chem 249: 4510 4514

20. Preedy VR, Garlick PJ (1985) The effect of glucagon administration on protein synthesis in skeletal muscles, heart and liver in vivo. Biochem J 228: 575-581

21. Fulks RM, Li JB, Goldberg AL (1975) Effects of insulin, glucose, and amino acids on protein turnover in rat diaphragm. $\mathbf{J}$ Biol Chem 250: 290-298

22. Petersen KF, Hansen BA, Vilstrup H (1987) Time dependent stimulating effect of glucagon on the capacity of Urea-N synthesis in rats. Horm Metab Res 19: 53-56

23. Hansen BA, Krog B, Vilstrup H (1986) Insulin and glucose decreases the capacity of urea- $\mathrm{N}$ synthesis in the rat. Scand J Clin Lab Invest 46: 599-603

24. Jefferson LS, Liao WSL, Peavy DE, Miller TB, Appel MC, Taylor JM (1983) Diabetes-induced alterations in liver protein synthesis. J Biol Chem 258: 1369-1375

25. Hensgens HESJ, Meijer AJ (1980) Inhibition of urea cycle activity by high concentrations of alanine. Biochem J 186: 1-4

Received: 1 February 1988

and in revised form: 14 September 1988

Dr. T.Almdal

Medical Department A-2151

Rigshospitalet

9 Blegdamsvej

DK-2100 Copenhagen

Denmark 